\title{
Electronic properties of a new family of Layered Materials from Groups 14-15: First-Principles Simulations
}

\section{Supporting Information}

Muhammad Sufyan Ramzan, ${ }^{+}$Vladimir Bacic, ${ }^{+}$Yu Jing, ${ }^{\neq}, \|$and Agnieszka Kuc ${ }^{*}+, \neq, \perp$

${ }^{+}$Department of Physics and Earth Sciences, Jacobs University Bremen, Campus Ring 1, 28759 Bremen, Germany

${ }^{\ddagger}$ Wilhelm-Ostwald-Institut für Physikalische und Theoretische Chemie, Universität Leipzig, Linnéstr. 2, 04103 Leipzig, Germany

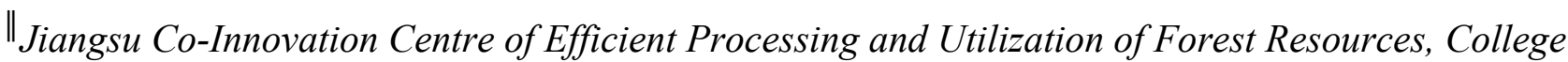
of Chemical Engineering, Nanjing Forestry University, Nanjing 210037, China

${ }^{\perp}$ Helmholtz-Zentrum Dresden-Rossendorf, Forschungsstelle Leipzig, Abteilung Reaktiver Transport, Permoserstr. 15, 04318 Leipzig, Germany

*Corresponding author: a.kuc@hzdr.de

(a)
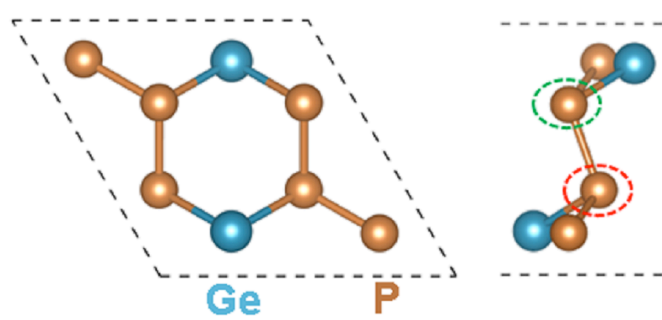

(c)
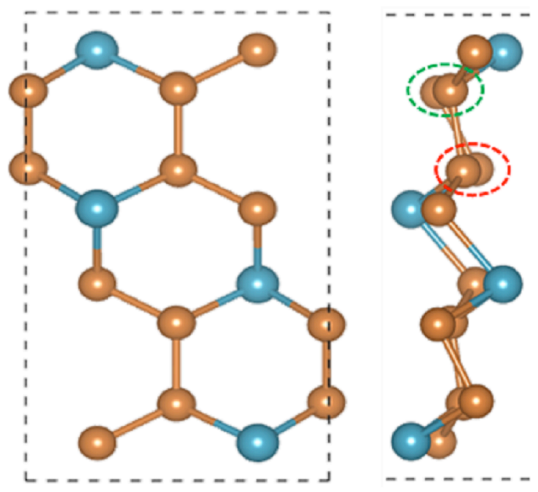

(b)

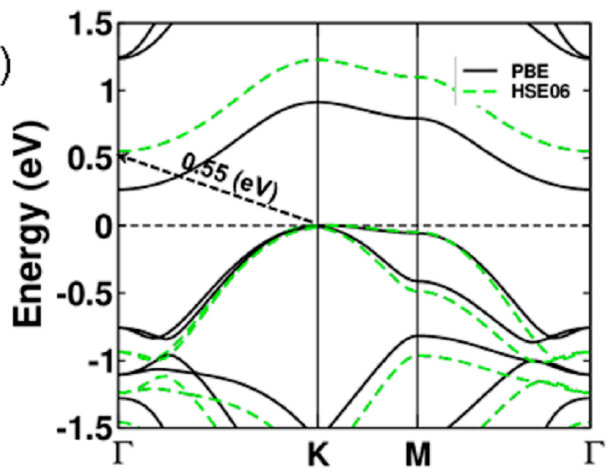

(d)

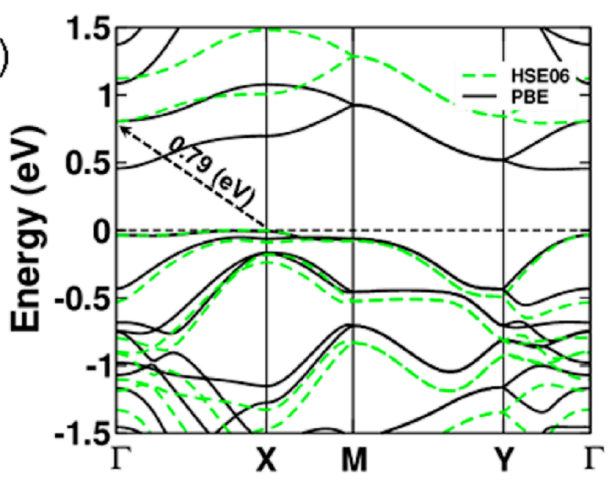

Figure S1. Exemplary case of the $\mathrm{GeP}_{3}$ crystal structure in the hexagonal unit cell (a) and the rectangular unit cell (c) representations. The corresponding band structures are shown in (b) and (d). Green and red dashed circles indicate the atoms that undergo displacements during the surface reconstruction in a monolayer form. Band structures were calculated at the PBE (black) and HSE06 (dashed green) levels of theory and arrows indicate the HSE06 band gaps. Fermi level is shifted to the valance band maximum, indicated by the horizontal dashed lines. 
Table S1. Calculated bond lengths $\mathrm{X}-\mathrm{Y}$ and $\mathrm{Y}-\mathrm{Y}$ in $\mathrm{XY}$ s systems $(\mathrm{X}-\mathrm{C}, \mathrm{Si}, \mathrm{Ge}, \mathrm{Sn}, \mathrm{Pb} ; \mathrm{Y}-\mathrm{P}, \mathrm{As}, \mathrm{Sb})$.

\begin{tabular}{|c|c|c|c|c|c|c|c|}
\hline \multirow{2}{*}{$\mathrm{X}$} & \multirow{2}{*}{ System } & \multicolumn{2}{|c|}{$\mathrm{XP}_{3}$} & \multicolumn{2}{|c|}{$\mathrm{XAs}_{3}$} & \multicolumn{2}{|c|}{$\mathrm{XSb}_{3}$} \\
\hline & & $\mathrm{P}-\mathrm{P}$ & $\mathrm{X}-\mathrm{P}$ & $\mathrm{As}-\mathrm{As}$ & $\mathrm{X}-\mathrm{As}$ & $\mathrm{Sb}-\mathrm{Sb}$ & $\mathrm{X}-\mathrm{Sb}$ \\
\hline \multirow{3}{*}{$\mathrm{C}$} & $1 \mathrm{~L}$ & 2.280 & 1.780 & 2.560 & 1.920 & 2.950 & 2.130 \\
\hline & $2 \mathrm{~L}$ & 2.280 & 1.780 & 2.550 & 1.920 & 2.950 & 2.130 \\
\hline & Bulk & 2.280 & 1.780 & 2.560 & 1.920 & 2.950 & 2.140 \\
\hline \multirow{3}{*}{$\mathrm{Si}$} & $1 \mathrm{~L}$ & 2.250 & 2.360 & 2.510 & 2.400 & 2.920 & 2.700 \\
\hline & $2 \mathrm{~L}$ & 2.220 & 2.350 & 2.480 & 2.470 & 2.880 & 2.670 \\
\hline & Bulk & 2.250 & 2.400 & 2.490 & 2.490 & 2.900 & 2.690 \\
\hline \multirow{3}{*}{$\mathrm{Ge}$} & $1 \mathrm{~L}$ & 2.160 & 2.510 & 2.450 & 2.590 & 2.890 & 2.760 \\
\hline & $2 \mathrm{~L}$ & 2.220 & 2.460 & 2.480 & 2.550 & 2.870 & 2.750 \\
\hline & Bulk & 2.230 & 2.480 & 2.490 & 2.590 & 2.890 & 2.780 \\
\hline \multirow{3}{*}{$\mathrm{Sn}$} & $1 \mathrm{~L}$ & 2.170 & 2.710 & 2.430 & 2.800 & 2.880 & 2.990 \\
\hline & $2 \mathrm{~L}$ & 2.220 & 2.630 & 2.480 & 2.780 & 2.860 & 2.950 \\
\hline & Bulk & 2.230 & 2.690 & 2.490 & 2.786 & 2.924 & 3.020 \\
\hline \multirow{3}{*}{$\mathrm{Pb}$} & $1 \mathrm{~L}$ & 2.170 & 2.790 & 2.430 & 2.880 & 2.870 & 3.080 \\
\hline & $2 \mathrm{~L}$ & 2.210 & 2.770 & 2.470 & 2.880 & 2.870 & 3.050 \\
\hline & Bulk & 2.220 & 2.820 & 2.480 & 2.890 & 2.900 & 3.090 \\
\hline
\end{tabular}

Table S2. Calculated lattice parameters of $\mathrm{XAs}_{3}$ (with X - C, Si, Ge, Sn, Pb) mono- $(a, b)$, bilayers $(a, b)$, and bulk (a, $\left.b, c\right)$ forms. For monolayer (1L), $a$ and $b$ lattice parameters are given for the rectangular unit cell representation, while for bilayer (2L) and bulk, hexagonal unit cells were used. Interlayer distances $(d)$ along the $\mathrm{z}$-axis are given for $2 \mathrm{~L}$ and bulks.

\begin{tabular}{|c|c|c|c|c|c|}
\hline \multirow{2}{*}{ System } & \multicolumn{3}{|c|}{ Lattice vectors $(\AA)$} & \multicolumn{2}{|c|}{$d(\AA)$} \\
\hline & $1 \mathrm{~L}_{(a, b)}$ & $2 \mathrm{~L}_{(a=b)}$ & $\operatorname{Bulk}_{(a=b, c)}$ & $2 \mathrm{~L}$ & Bulk \\
\hline $\mathrm{CAs}_{3}$ & $6.778,11.740$ & 6.769 & $6.818,11.757$ & 2.551 & 2.441 \\
\hline $\mathrm{SiAs}_{3}$ & $7.339,12.710$ & 7.293 & $7.417,10.219$ & 1.996 & 2.077 \\
\hline $\mathrm{GeAs}_{3}$ & $7.506,12.877$ & 7.424 & $7.542,10.435$ & 2.170 & 2.045 \\
\hline $\mathrm{SnAs}_{3}$ & $7.695,13.222$ & 7.715 & $7.869,10.771$ & 2.152 & 1.992 \\
\hline $\mathrm{PbAs}_{3}$ & $7.755,13.457$ & 7.862 & $8.091,11.010$ & 2.312 & 2.104 \\
\hline
\end{tabular}


Table S3. Calculated lattice parameters of $\mathrm{XSb}_{3}$ (with X - C, Si, Ge, Sn, Pb) mono- $(a, b)$, bilayers $(a, b)$, and bulk (a, $\left.b, c\right)$ forms. For monolayer (1L), $a$ and $b$ lattice parameters are given for the rectangular unit cell representation, while for bilayer (2L) and bulk, hexagonal unit cells were used. Interlayer distances $(d)$ along the $\mathrm{z}$-axis are given for $2 \mathrm{~L}$ and bulks.

\begin{tabular}{|c|c|c|c|c|c|}
\hline \multirow{2}{*}{ System } & \multicolumn{3}{|c|}{ Lattice vectors $(\AA)$} & \multicolumn{2}{|c|}{$d(\AA)$} \\
\hline & $1 \mathrm{~L}_{(a, b)}$ & $2 \mathrm{~L}_{(a=b)}$ & $\operatorname{Bulk}_{(a=b, c)}$ & $2 \mathrm{~L}$ & Bulk \\
\hline $\mathrm{CSb}_{3}$ & $7.588,13.129$ & 7.594 & $7.735,12.588$ & 2.744 & 2.531 \\
\hline $\mathrm{SiSb}_{3}$ & $7.416,13.042$ & 8.124 & $8.274,11.391$ & 2.263 & 2.311 \\
\hline $\mathrm{GeSb}_{3}$ & $7.479,13.228$ & 8.214 & $8.364,11.455$ & 2.214 & 2.163 \\
\hline $\mathrm{SnSb}_{3}$ & $7.665,13.573$ & 8.467 & $8.668,11.041$ & 2.272 & 2.054 \\
\hline $\mathrm{PbSb}_{3}$ & $7.780,13.760$ & 8.509 & $8.794,11.340$ & 2.357 & 2.130 \\
\hline
\end{tabular}

Table S4. Calculated total valance charge $(\mathrm{q})$ and the Bader atomic charges of P-rings $\left(\mathrm{Y}_{6}\right)$ of $\mathrm{XP}_{3} 1 \mathrm{~L}, 2 \mathrm{~L}$, and bulks, together with the charge difference $(\Delta \mathrm{q})$. Here, positive values of $\Delta \mathrm{q}$ indicate the charge transfer from the P-ring towards $\mathrm{X}$ atoms and the negative values indicate the charge transfer from the $\mathrm{X}$ atoms to the P-rings.

\begin{tabular}{clccc}
\hline \multicolumn{2}{c}{ System } & Valance q (P-ring) & Bader q (P-ring) & $\Delta \mathrm{q}_{(\mathrm{e})}$ \\
\hline \multirow{3}{*}{$\mathrm{CP}_{3}$} & $1 \mathrm{~L}$ & 30.00 & 26.70 & 3.30 \\
& $2 \mathrm{~L}$ & 30.00 & 26.78 & 3.22 \\
& Bulk & 30.00 & 26.78 & 3.22 \\
\hline \multirow{3}{*}{$\mathrm{SiP}_{3}$} & $1 \mathrm{~L}$ & 30.00 & 32.20 & -2.19 \\
& $2 \mathrm{~L}$ & 30.00 & 32.07 & -2.07 \\
& Bulk & 30.00 & 31.97 & -1.97 \\
\hline \multirow{3}{*}{$\mathrm{GeP}_{3}$} & $1 \mathrm{~L}$ & 30.00 & 31.03 & -1.03 \\
& $2 \mathrm{~L}$ & 30.00 & 31.13 & -1.13 \\
& Bulk & 30.00 & 31.16 & -1.16 \\
\hline \multirow{3}{*}{$\mathrm{SnP}_{3}$} & $1 \mathrm{~L}$ & 30.00 & 31.34 & -1.34 \\
& 2L & 30.00 & 31.16 & -1.60 \\
& Bulk & 30.00 & 31.68 & -1.68 \\
\hline \multirow{3}{*}{$\mathrm{PbP}_{3}$} & $1 \mathrm{~L}$ & 30.00 & 31.32 & -1.32 \\
& 2L & 30.00 & 31.39 & -1.39 \\
& Bulk & 30.00 & 31.48 & -1.48 \\
\hline
\end{tabular}


Table S5. Calculated total valance charge (q) and the Bader atomic charges of As-rings $\left(\mathrm{Y}_{6}\right)$ of $\mathrm{XAs}_{3}$ monolayers, together with the charge difference $(\Delta q)$. Here, positive values of $\Delta \mathrm{q}$ indicate the charge transfer from the As-ring towards $X$ atoms and the negative values indicate the charge transfer from the $\mathrm{X}$ atoms to the As-rings.

\begin{tabular}{cccc}
\hline System $_{(1 \mathrm{~L})}$ & valance_q (As-ring) & Bader_q (As-ring) & $\Delta \mathrm{q}_{(\mathrm{e})}$ \\
\hline $\mathrm{CAs}_{3}$ & 30.00 & 27.94 & 2.06 \\
$\mathrm{SiAs}_{3}$ & 30.00 & 31.14 & -1.14 \\
$\mathrm{GeAs}_{3}$ & 30.00 & 30.55 & -0.55 \\
$\mathrm{SnAs}_{3}$ & 30.00 & 31.06 & -1.06 \\
$\mathrm{PbAs}_{3}$ & 30.00 & 31.03 & -1.03 \\
\hline
\end{tabular}
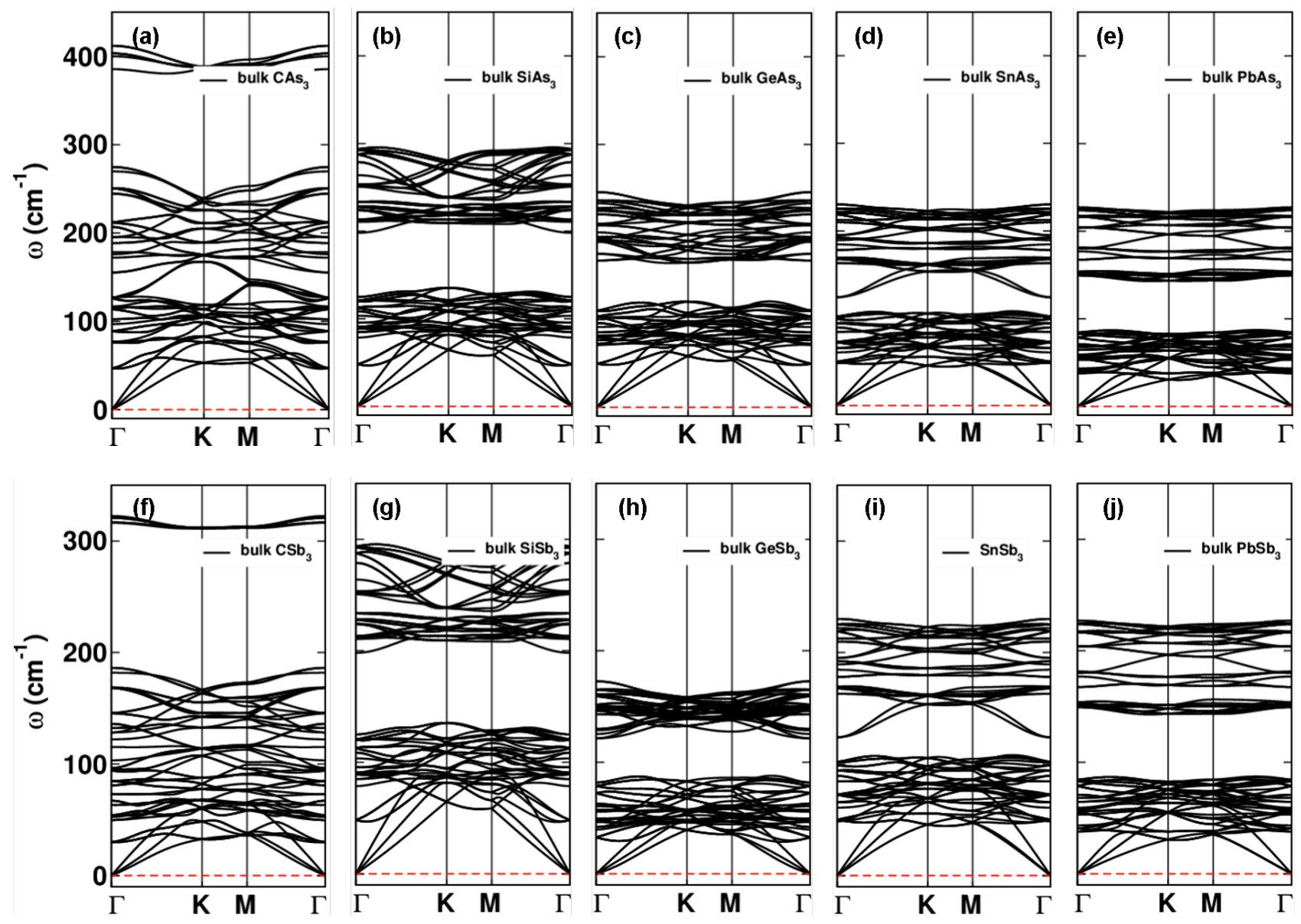

Figure S2. Calculated phonon dispersion relations of (a) - (e) bulk XAs 3 and (f)-(j) bulk $\mathrm{XSb}_{3}$ with $2 \times 2 \times 2$ supercells. All phonons have real frequencies indicating stability of these materials in bulk forms. 
Calculation of cleavage energy: Cleavage energies were calculated using 5 layer system, which represents bulk-like form, and $1 \mathrm{~L}$ or $2 \mathrm{~L}$ layers were moved away from the remaining layers as shown in the inset of Figure 2 in main text and Figure S3. Cleavage energies were calculated using the following formula:

$$
E_{\text {Cleavage }}=\frac{\left(E_{5 L+d}-E_{5 L}\right)}{A}
$$

where $E_{\text {Cleavage }}, E_{5 \mathrm{~L}+\mathrm{d}}, \mathrm{E}_{5 \mathrm{~L}}$, and $\mathrm{A}$ correspond to the cleavage energy, the total energy of 5L slab with and without displacement, and the total area of the unit cell, respectively. Note that these cleavage energies were calculated in the hexagonal unit cell representation, which means that in this case, for monolayer cleavage, the surface reconstruction was not considered. This, however, should not change our conclusions about the possible exfoliation of mono- or bilayers. Since the reconstruction lowers the energy of the monolayers, we have estimated the upper bound of the cleavage energies for these systems.
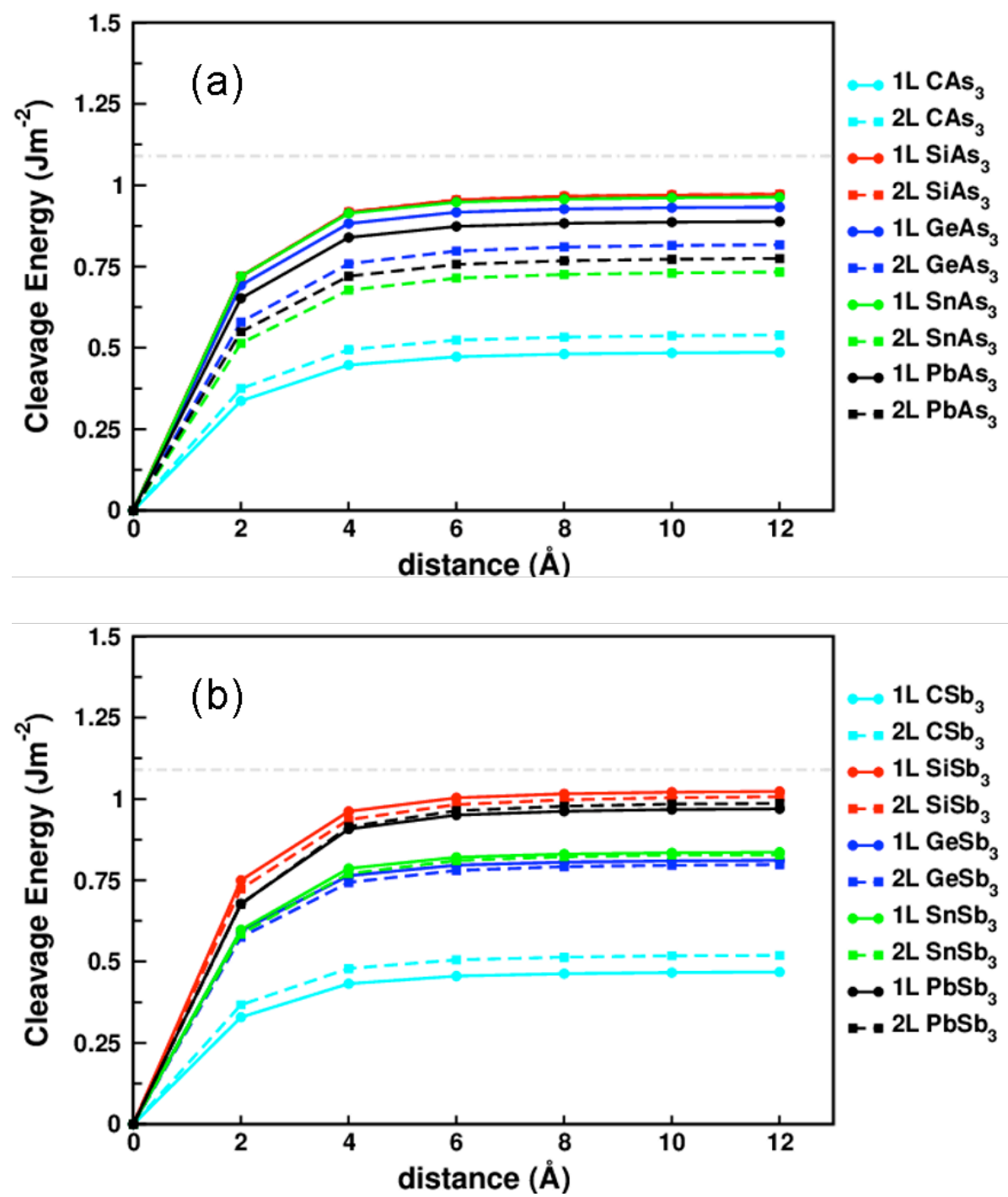

Figure S3. Calculated cleavage energies of (a) $\mathrm{XAs}_{3}$ and (b) $\mathrm{XSb}_{3}(\mathrm{X}-\mathrm{C}, \mathrm{Si}, \mathrm{Ge}, \mathrm{Sn}, \mathrm{Pb}) 1 \mathrm{~L}$ and $2 \mathrm{~L}$ shown as solid and dashed lines, respectively, as function of the separation distance between $1 \mathrm{~L}$ or $2 \mathrm{~L}$ and the remainder of $5 \mathrm{~L}$ slab. The distance zero refers to the equilibrium distance of bulk-like 5L-slab. Grey dashed line indicates the threshold energy for mechanically cleavable materials. The calculated cleavage energies fall below the threshold, suggesting that all systems should be cleavable from their bulk or multilayer stacks. 

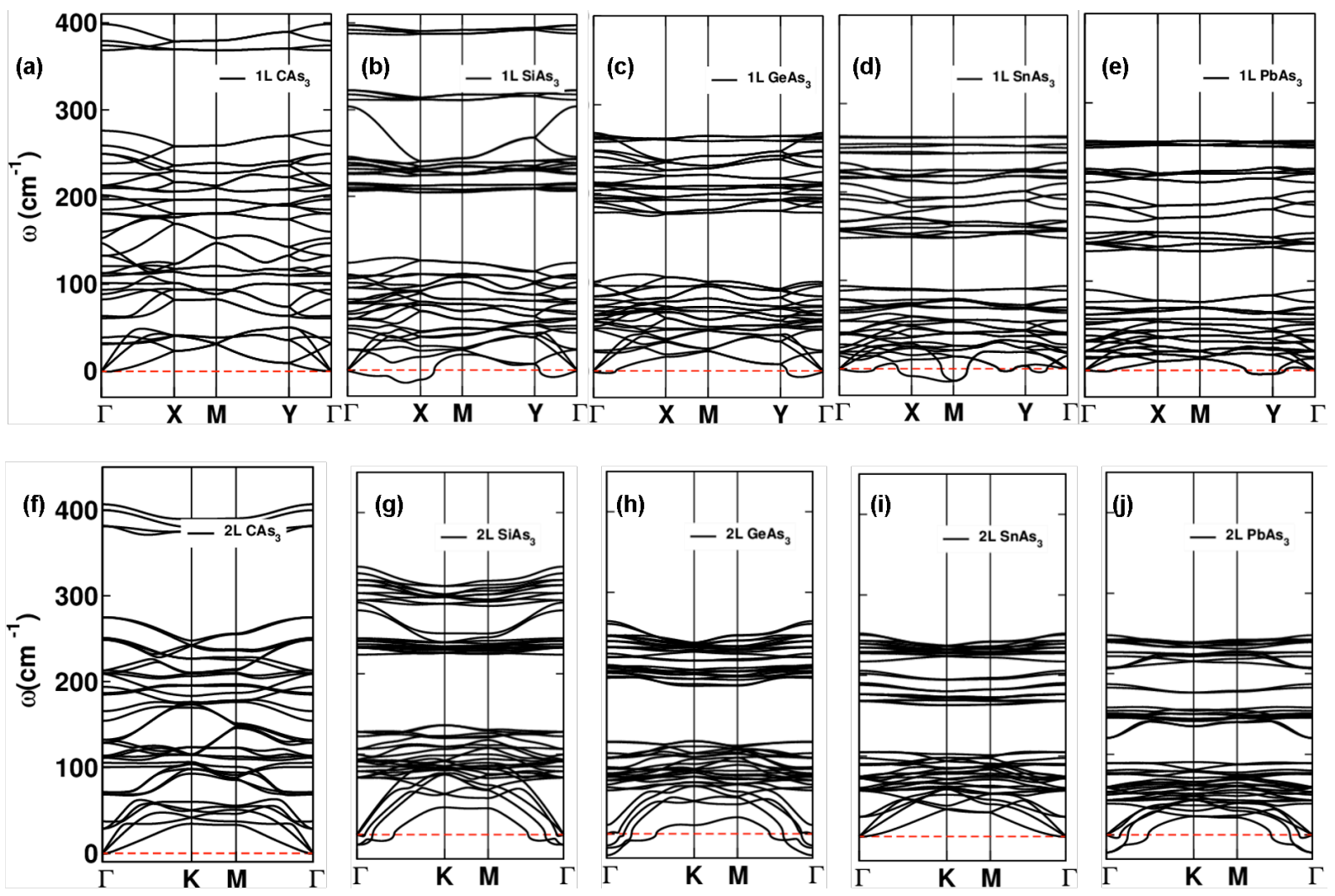

Figure S4. Phonon dispersion relation of monolayer (a)-(e) and (f)-(j) bilayer $\mathrm{XAs}_{3}$. For $1 \mathrm{~L}$ and $2 \mathrm{~L}$ systems, the $2 \times 3 \times 1$ and $3 \times 3 \times 1$ supercells were used, respectively; except for $2 \mathrm{~L} \mathrm{CAs}_{3}$, for which $4 \times 4 \times 1$ supercell was required. The only stable materials, from the point of view of phonon real frequencies, are $2 \mathrm{~L} \mathrm{CAs}_{3}$ and $\mathrm{SnAS}_{3}$, and $1 \mathrm{~L} \mathrm{CAs}_{3}$ and possibly $\mathrm{GeAs}_{3}$ (if the unit cells could be further enlarged for these simulations).
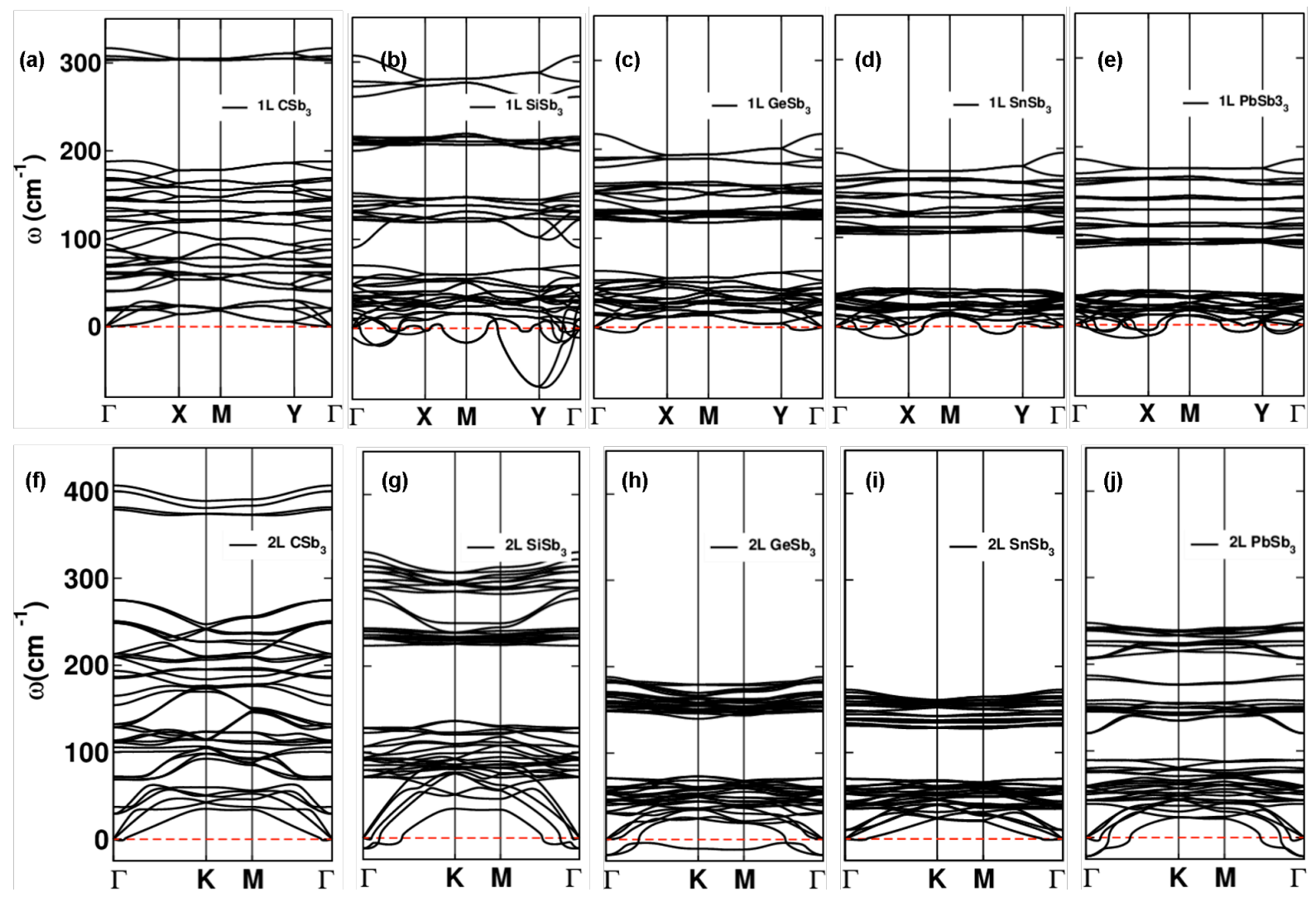

Figure S5. Phonon dispersion relation of monolayer (a)-(e) and (f)-(j) bilayer $\mathrm{XSb}_{3}$. For $1 \mathrm{~L}$ and $2 \mathrm{~L}$ systems, the $2 \times 3 \times 1$ and $3 \times 3 \times 1$ supercells were used, respectively; except for $1 \mathrm{~L} \mathrm{CSb}_{3}$, for which $2 \times 5 \times 1$ supercell was required. The only stable materials, from the point of view of phonon real frequencies, are $2 \mathrm{~L} \mathrm{CSb}_{3}$ and $\mathrm{SnSb}_{3}$, and $1 \mathrm{~L} \mathrm{CSb}_{3}$ and possibly $\mathrm{GeSb}_{3}$ (if the unit cells could be further enlarged for these simulations). 

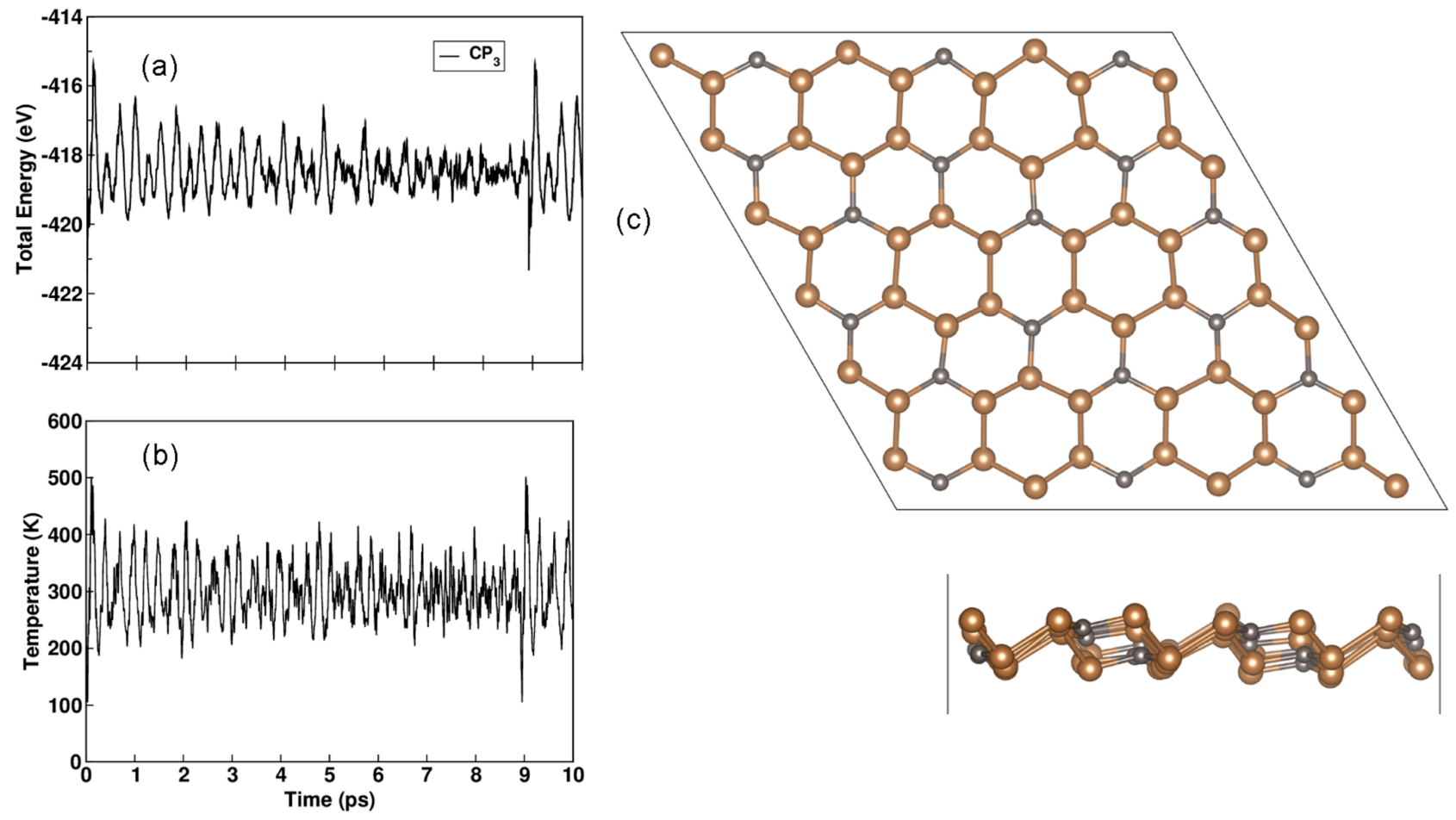

Figure S6. Ab-initio molecular dynamic (MD) simulations for $1 \mathrm{~L} \mathrm{CP}_{3}$ at $300 \mathrm{~K}$ showing change in (a) total energy and (b) temperature as time evolution. (c) Snapshot of $3 \times 3 \times 1$ supercell of $1 \mathrm{~L} \mathrm{CP}_{3}$ crystal structure at the end of the MD simulations. Here, grey (brown) indicates $\mathrm{C}(\mathrm{P})$ atoms. This material is stable at $300 \mathrm{~K}$.
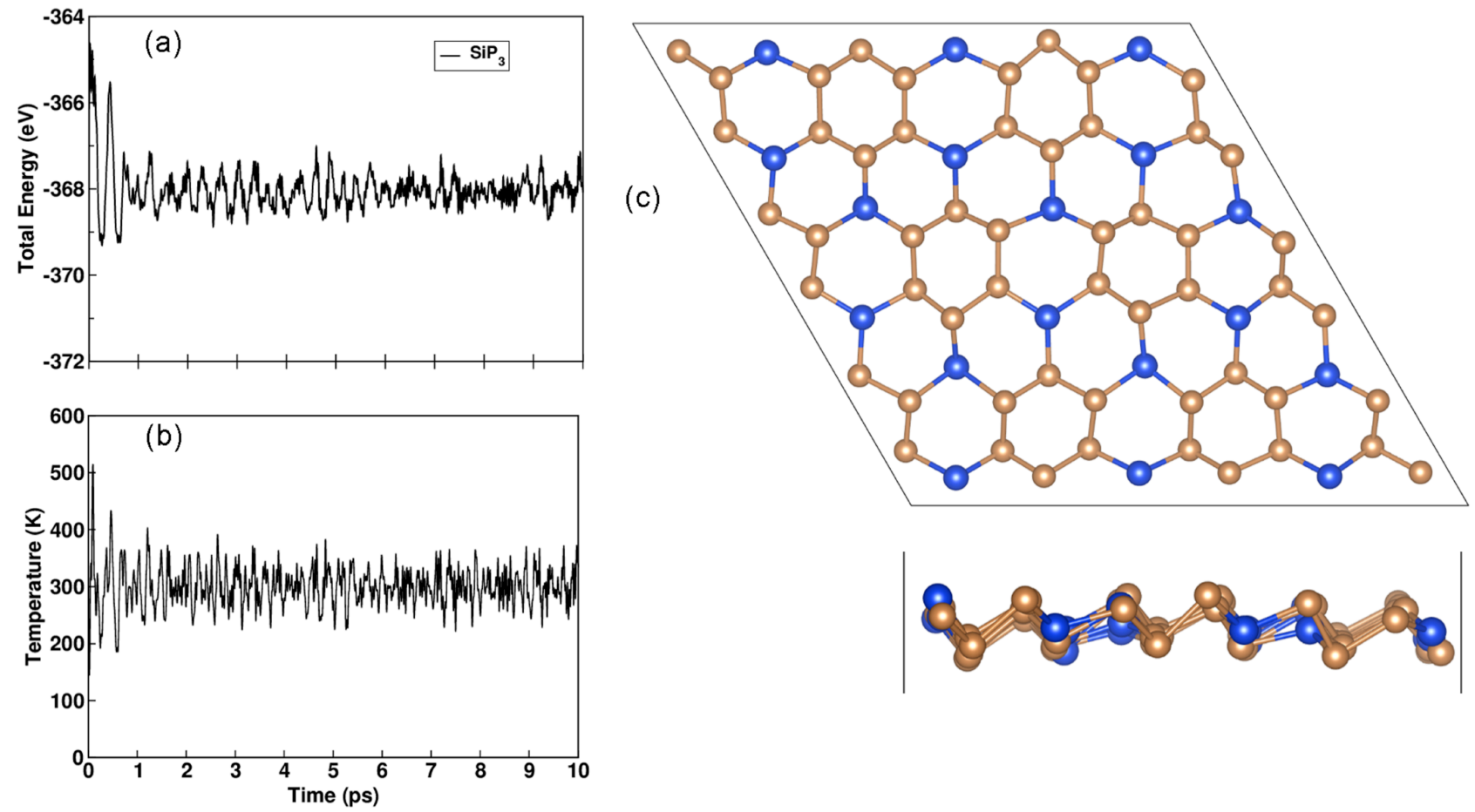

Figure S7. Ab-initio molecular MD simulations for $1 \mathrm{~L} \mathrm{SiP}_{3}$ at $300 \mathrm{~K}$ showing change in (a) total energy and (b) temperature as time evolution. (c) Snapshot of $3 \times 3 \times 1$ supercell of $1 \mathrm{~L} \mathrm{SiP}_{3}$ crystal structure at the end of the MD simulations. Here, blue (brown) indicates $\mathrm{Si}(\mathrm{P})$ atoms. This material is stable at $300 \mathrm{~K}$. 

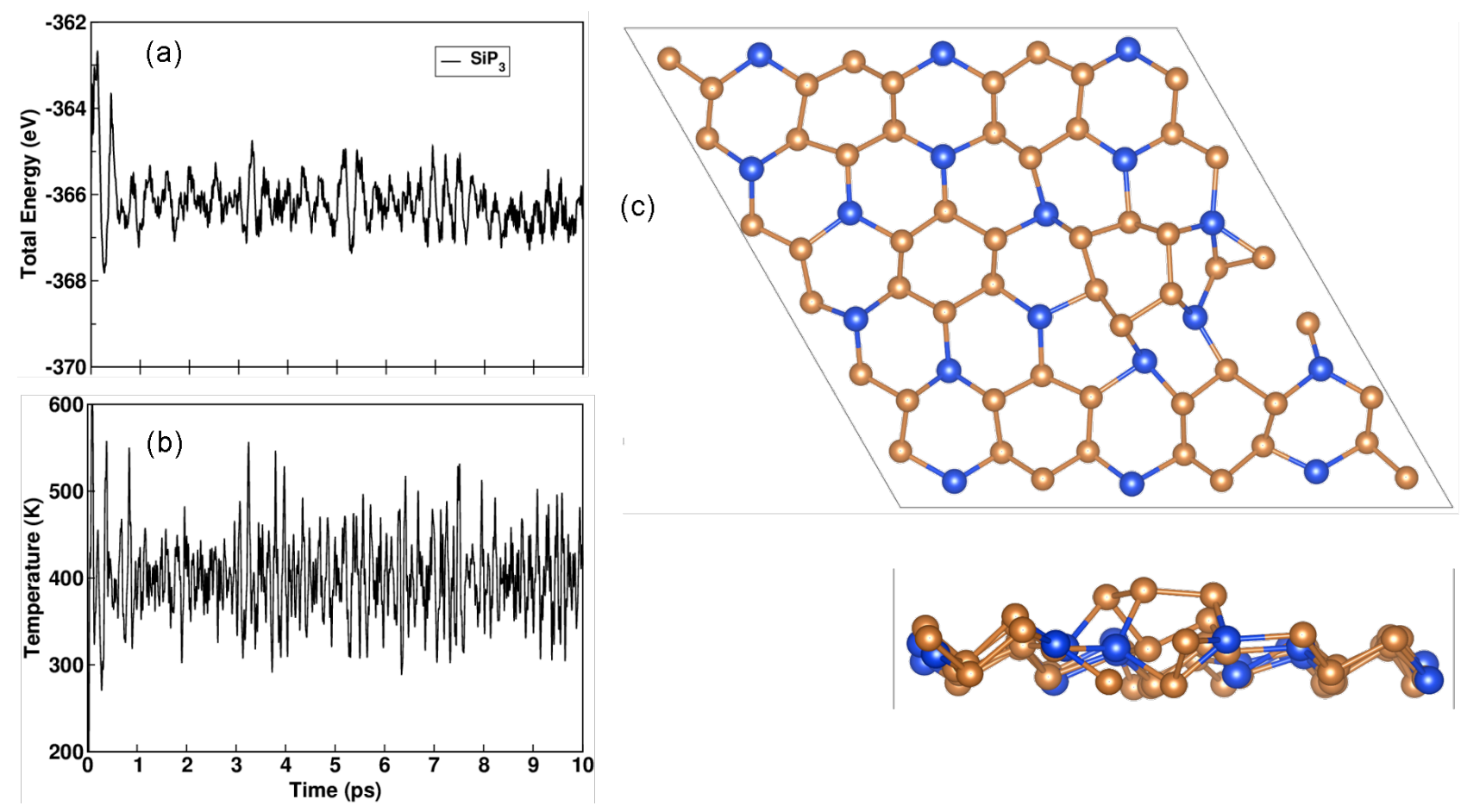

Figure S8. Ab-initio MD simulations for $1 \mathrm{~L} \mathrm{SiP}_{3}$ at $400 \mathrm{~K}$ showing change in (a) total energy and (b) temperature as time evolution. (c) Snapshot of $3 \times 3 \times 1$ supercell of $1 \mathrm{~L} \mathrm{SiP}_{3}$ crystal structure at the end of the MD simulations. Here, blue (brown) indicates Si (P) atoms. This material is instable at $400 \mathrm{~K}$.
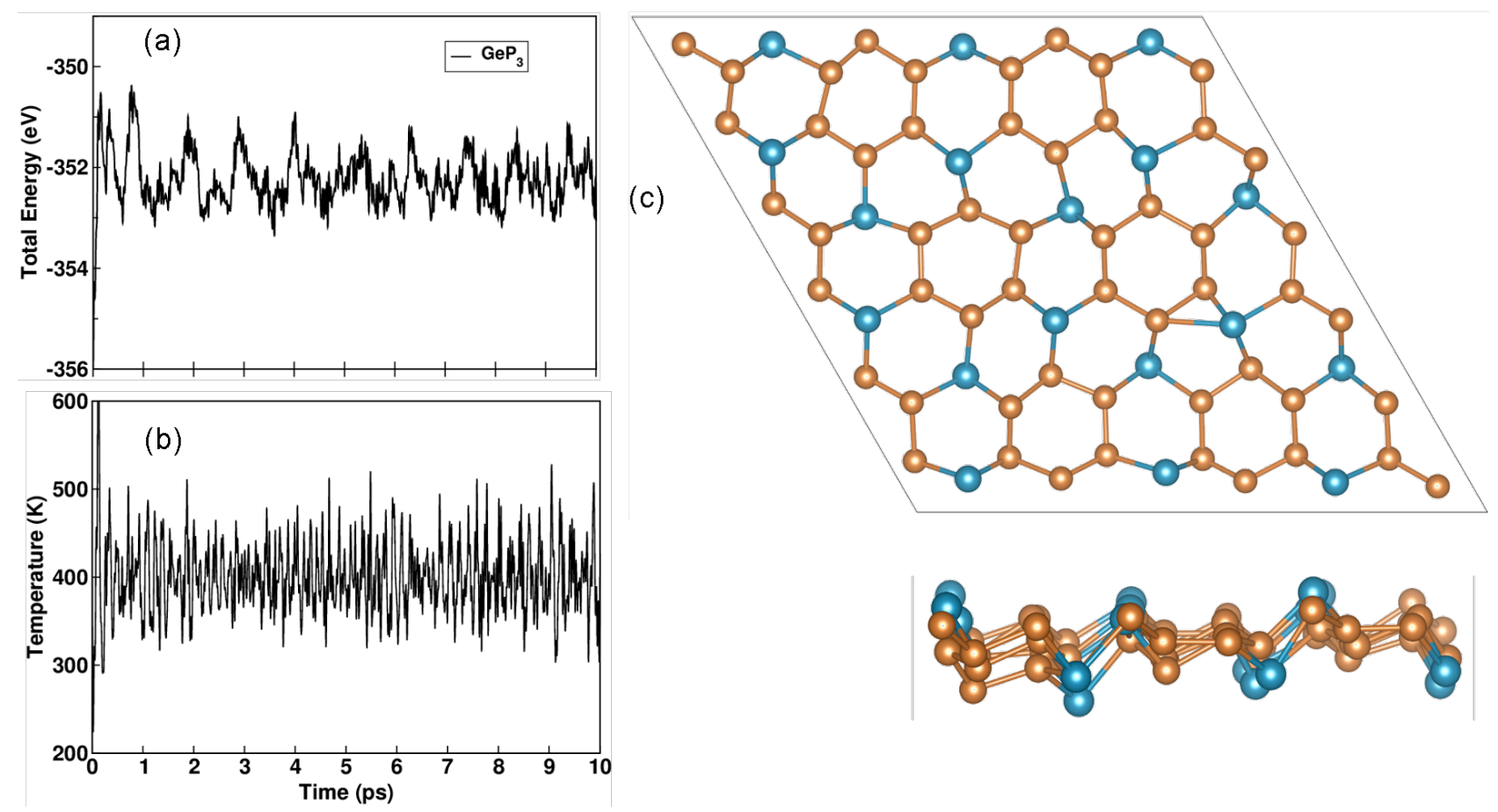

Figure S9. Ab-initio MD simulations of $1 \mathrm{~L} \mathrm{GeP}_{3}$ at $400 \mathrm{~K}$ showing change in (a) total energy and (b) temperature as time evolution. (c) Snapshot of $3 \times 3 \times 1$ supercell of $1 \mathrm{~L} \mathrm{GeP}_{3}$ crystal structure at the end of the MD simulation. Here, cyan (brown) indicates $\mathrm{Ge}(\mathrm{P})$ atoms. This material is stable at $400 \mathrm{~K}$. 

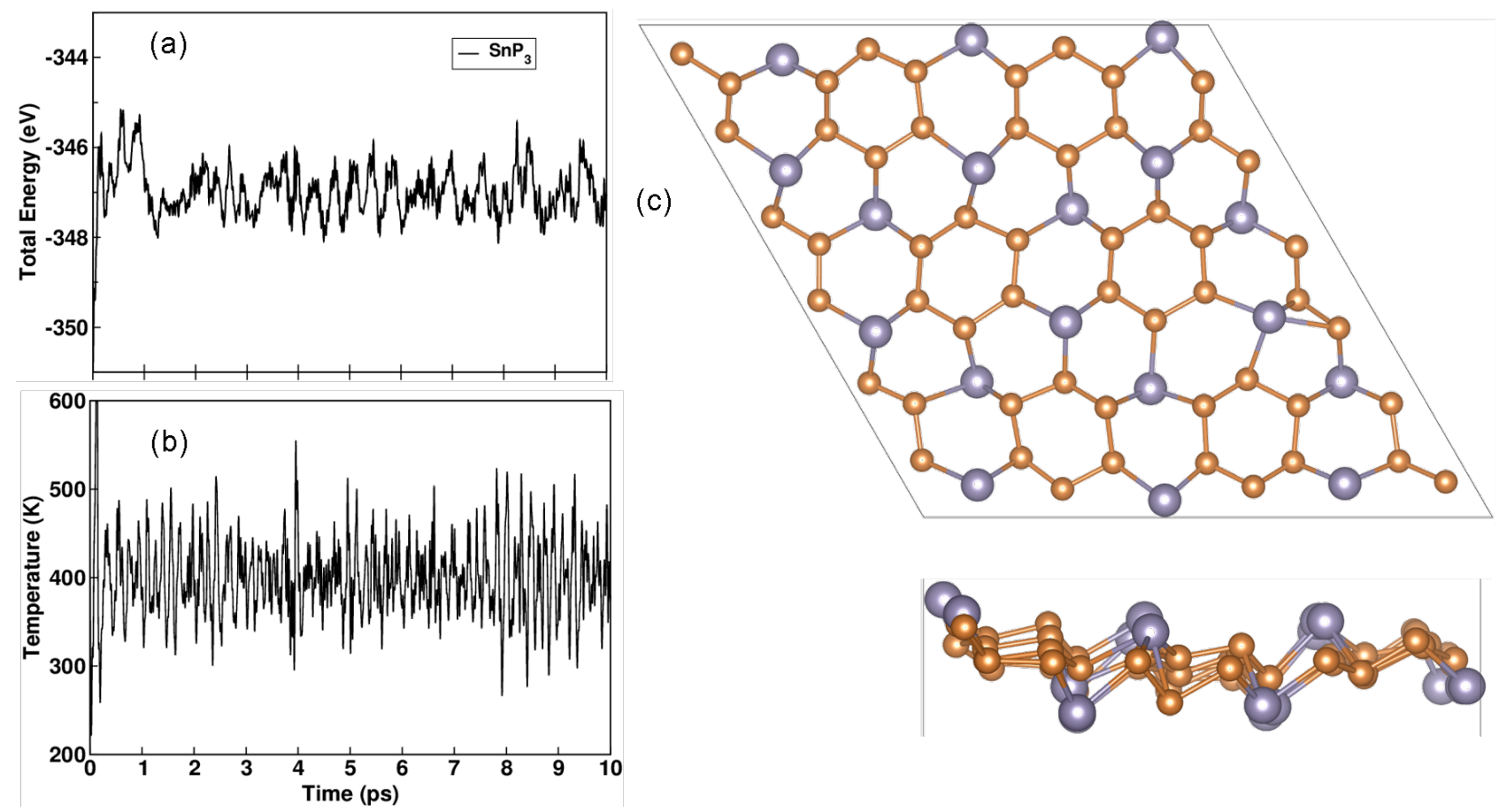

Figure S10. Ab-initio MD simulations of $1 \mathrm{~L} \mathrm{SnP}_{3}$ at $400 \mathrm{~K}$ showing change in (a) total energy and (b) temperature as time evolution. (c) Snapshot of $3 \times 3 \times 1$ supercell of $1 \mathrm{~L} \mathrm{SnP}_{3}$ crystal structure at the end of the $\mathrm{MD}$ simulation. Here, violet (brown) indicates $\mathrm{Sn}(\mathrm{P})$ atoms. This material is stable at $400 \mathrm{~K}$.
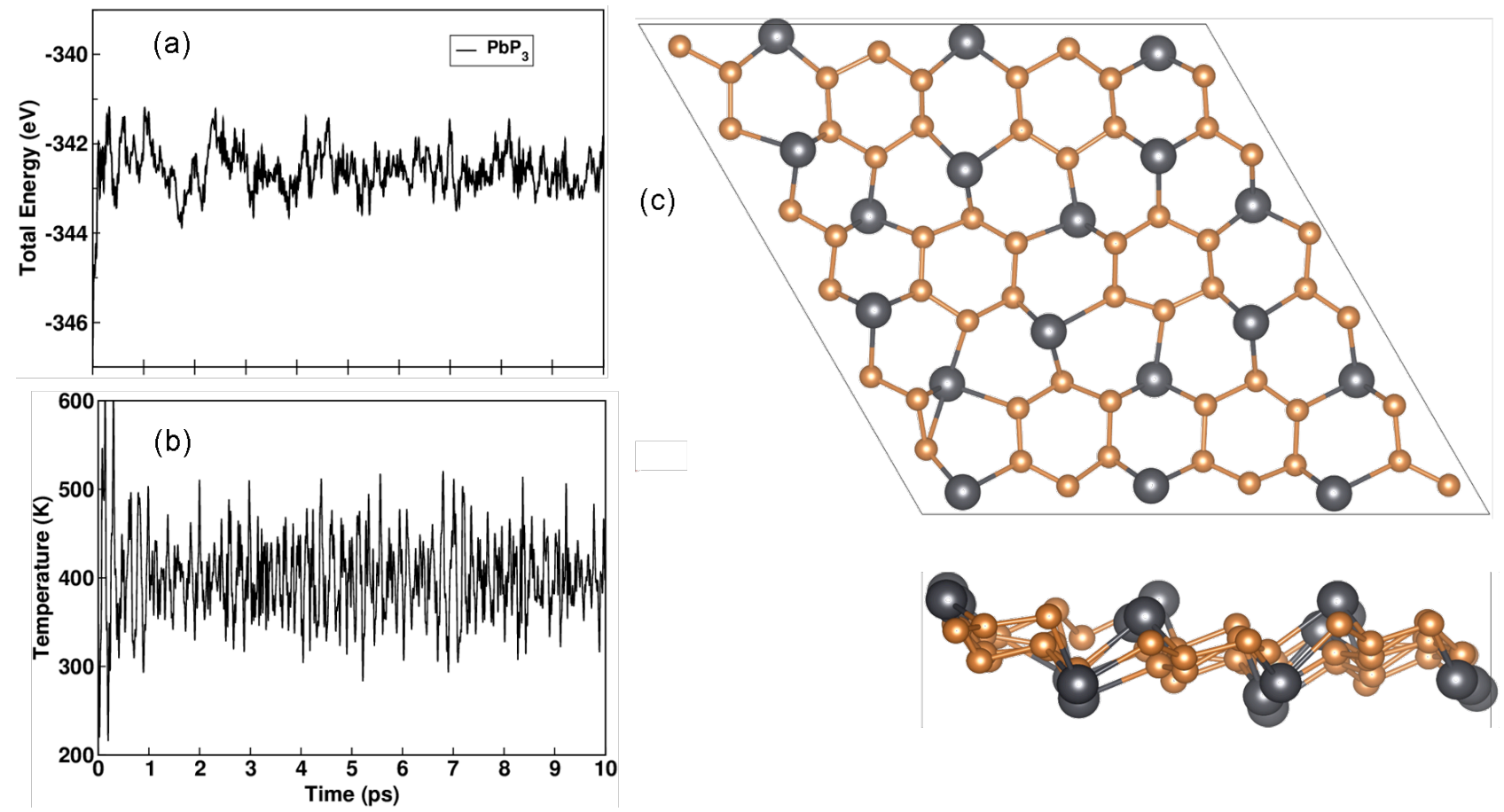

Figure S11. Ab-initio MD simulations of $1 \mathrm{~L} \mathrm{PbP}_{3}$ at $400 \mathrm{~K}$ showing change in (a) total energy and (b) temperature as time evolution. (c) Snapshot of $3 \times 3 \times 1$ supercell of $1 \mathrm{~L} \mathrm{PbP}_{3}$ crystal structure at the end of the $\mathrm{MD}$ simulation. Here, black (brown) indicates $\mathrm{Pb}(\mathrm{P})$ atoms. This material is stable at $400 \mathrm{~K}$. 

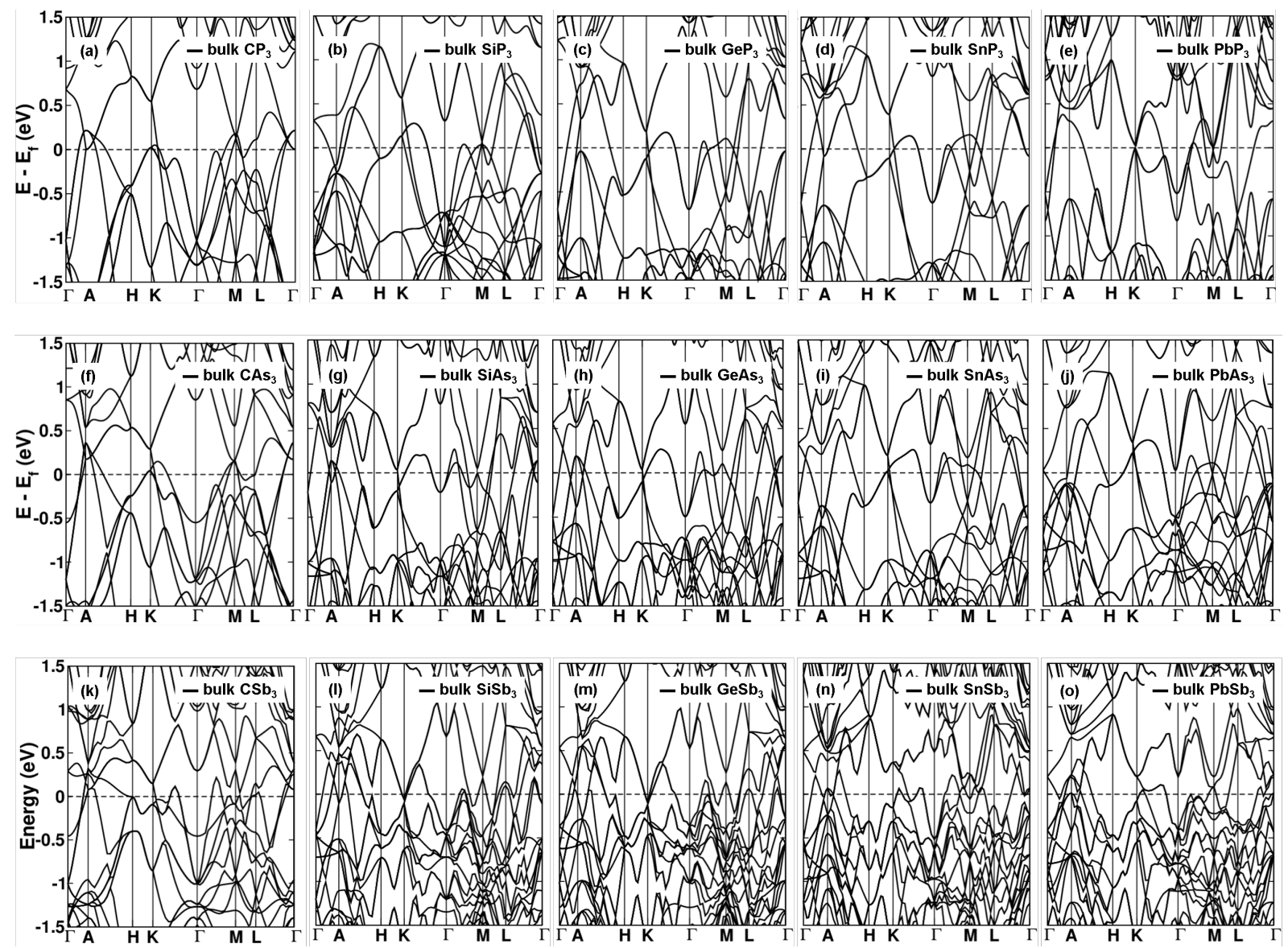

Figure S12. Electronic band structures of bulk $\mathrm{XP}_{3}(\mathrm{a})-(\mathrm{e})$, bulk XAs $3(\mathrm{f})-(\mathrm{j})$, and bulk $\mathrm{XSb}_{3}(\mathrm{k})-(\mathrm{o})$, calculated at the PBE level of theory. Horizontal dashed lines represent Fermi-levels in each system.
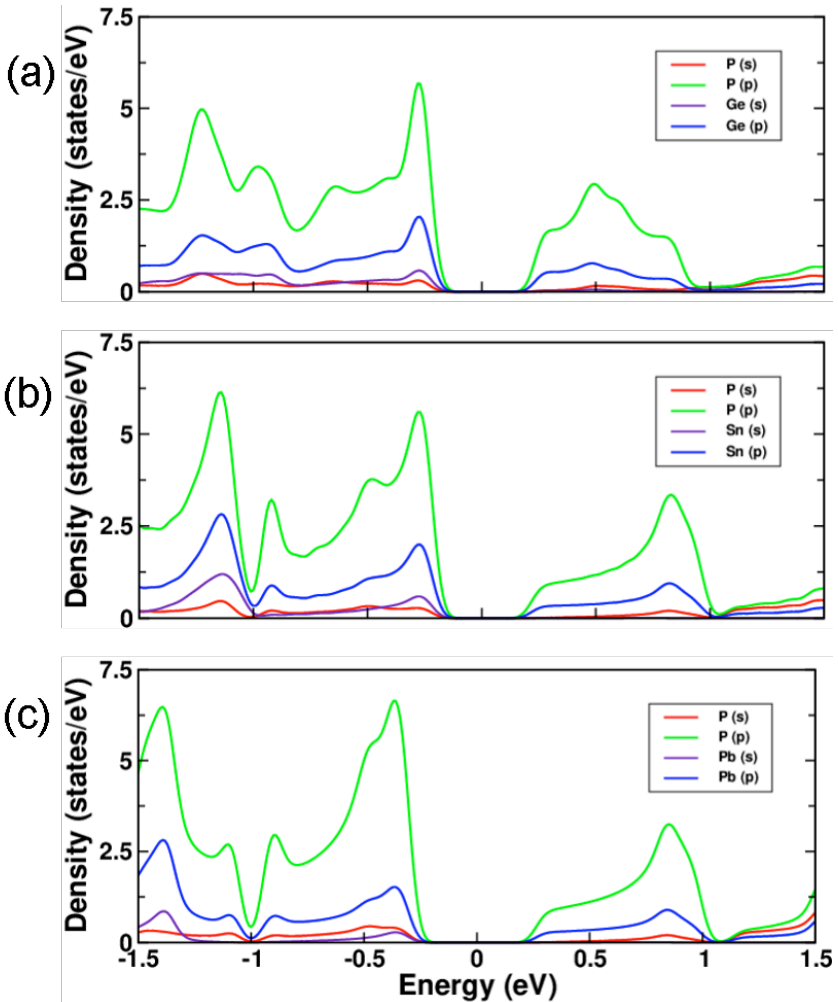

Figure S13. Projected density of states of (a) $1 \mathrm{~L} \mathrm{GeP}_{3}$, (b) $1 \mathrm{~L} \mathrm{SnP}_{3}$, and (c) $1 \mathrm{~L} \mathrm{PbP}_{3}$, calculated at the PBE level of theory. Fermi levels are set to zero. The frontier orbitals close to the Fermi level are predominantly the $\mathrm{P}$ and $\mathrm{X} p$-orbitals $(\mathrm{X}-\mathrm{Ge}, \mathrm{Sn}, \mathrm{Pb})$. 

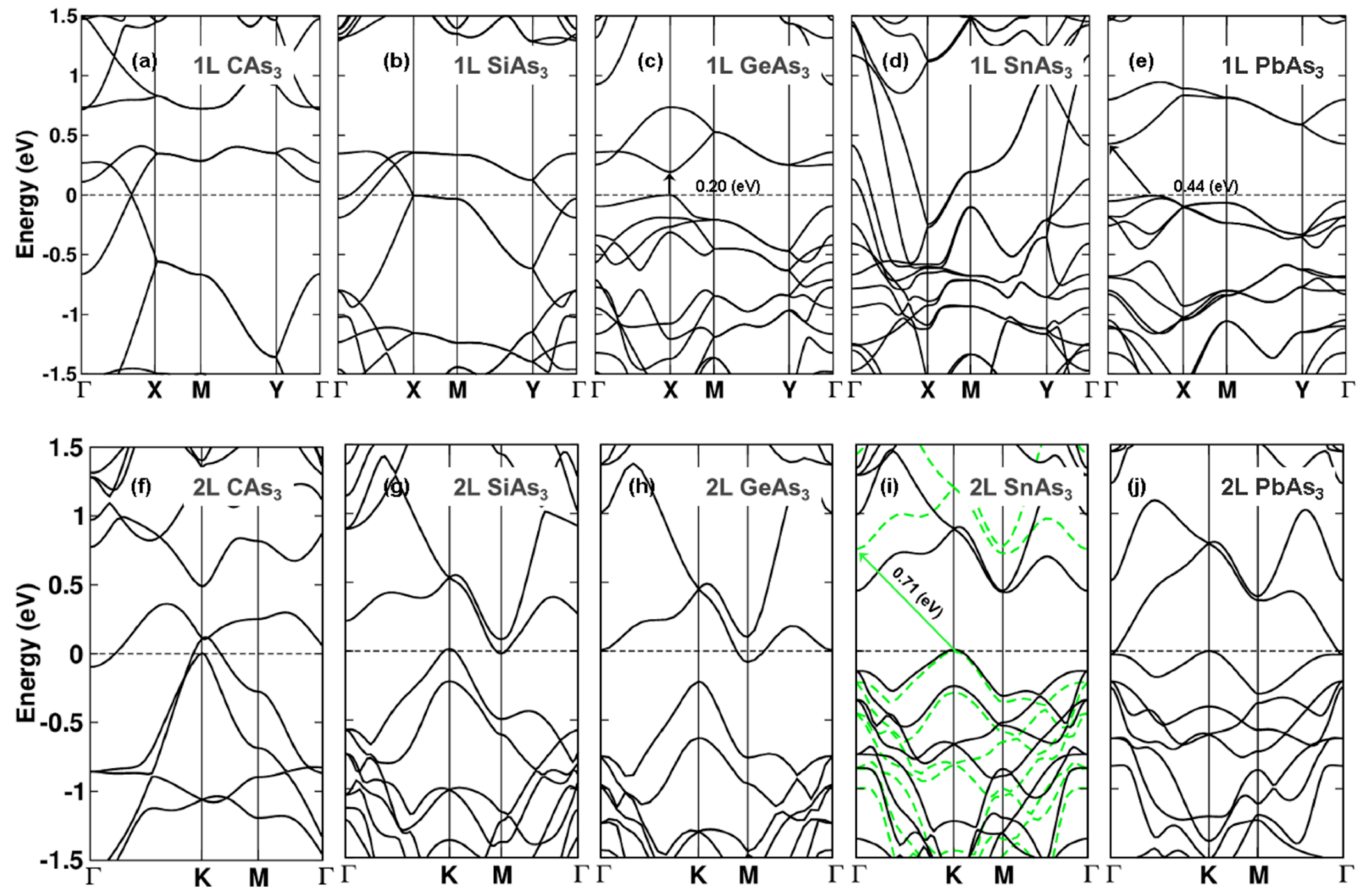

Figure S14. Band structures calculated at the PBE level of theory for (a)-(e) monolayer and (f)-(j) bilayer XAs 3 . The horizontal dashed lines indicate the Fermi levels. For the stable semiconducting $2 \mathrm{~L} \mathrm{SnAs}_{3}$, the HSE06 calculations are shown in green.
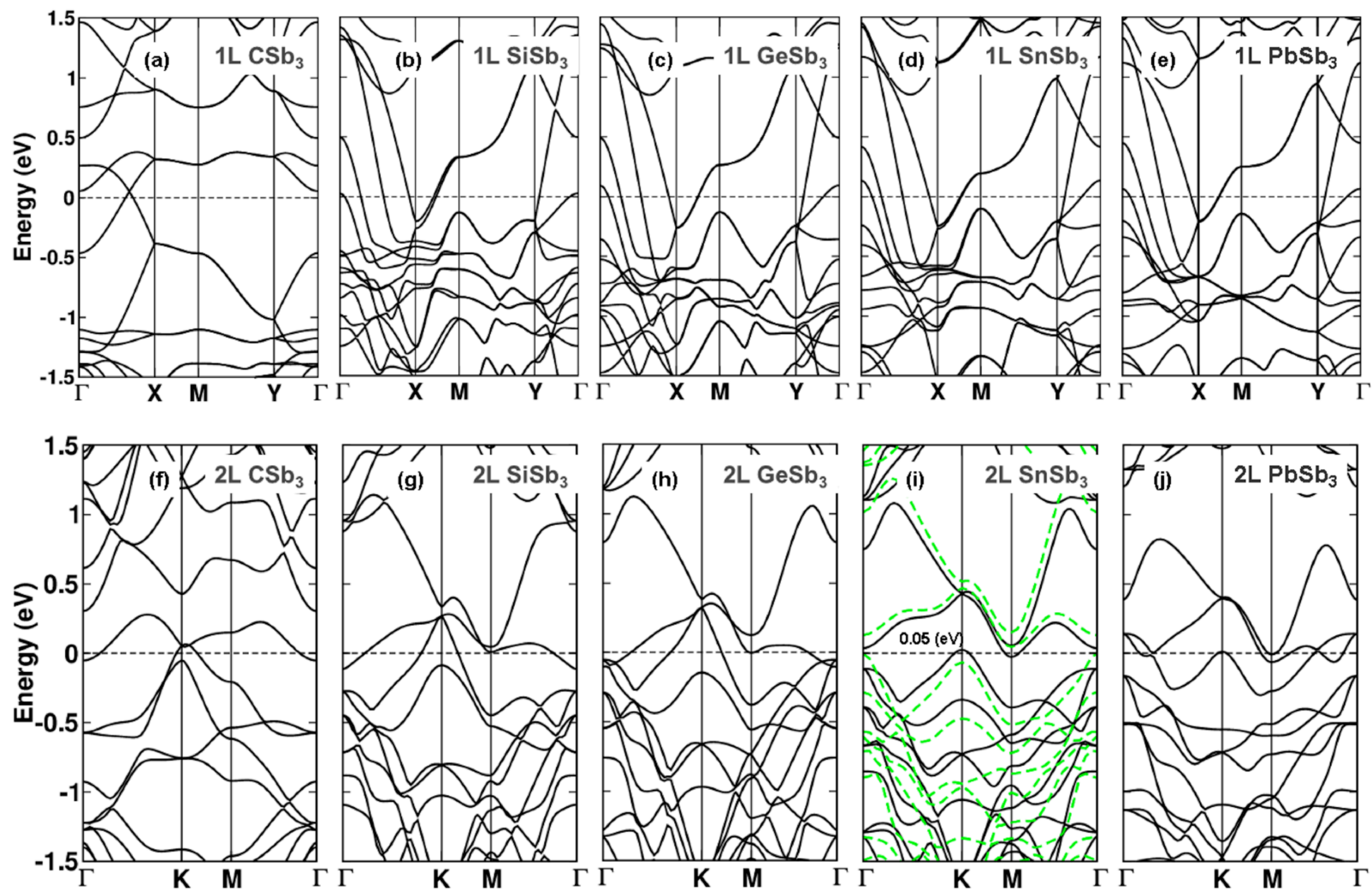

Figure S15. Band structures calculated at the PBE level of theory for (a)-(e) monolayer and (f)-(j) bilayer $\mathrm{XSb}_{3}$. The horizontal dashed lines indicate the Fermi levels. For the stable semiconducting $2 \mathrm{~L} \mathrm{SnSb}_{3}$, the HSE06 calculations are shown in green. 

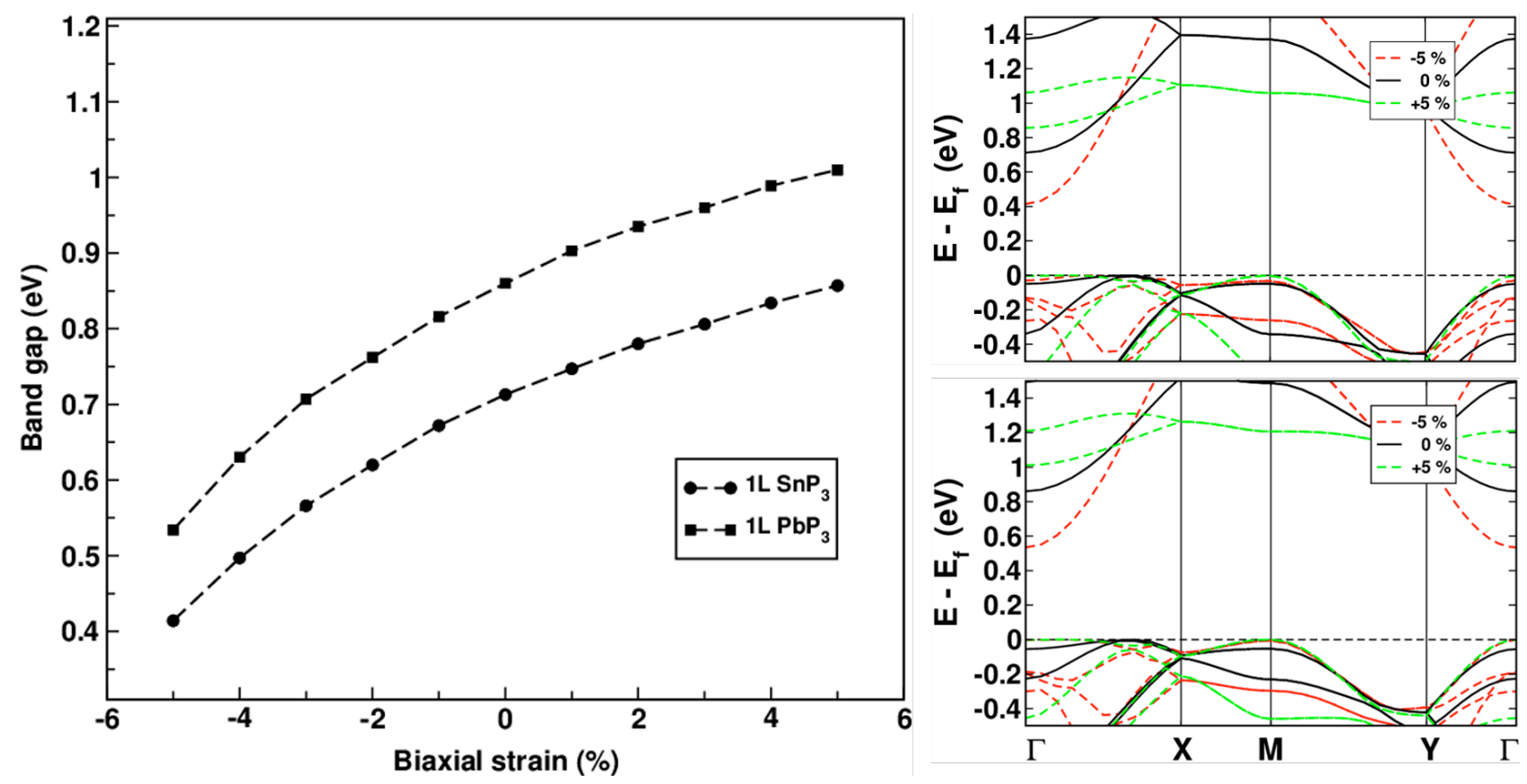

Figure S16. (Right) Effect of compressive and tensile strain on the band gap of exemplary $1 \mathrm{~L} \mathrm{SnP}_{3}$ and $1 \mathrm{~L} \mathrm{PbP}$, calculated at the $\mathrm{HSE} 06$ level of theory. (Left) The band structures of unstrained, $5 \%$ compressive, and $5 \%$ tensile strained $1 \mathrm{~L} \mathrm{SnP}_{3}\left(\right.$ top) and $1 \mathrm{~L} \mathrm{PbP} \mathrm{P}_{3}(\mathrm{bottom})$. 